\title{
Multi-facet expressions of adenylate cyclase isoforms in B16- F10 melanoma cells differentiated by forskolin treatment
}

\author{
Du-Hyong Cho', Chang-Dae Bae ${ }^{2}$ \\ and Yong-Sung Juhnn ${ }^{1,3}$ \\ ${ }^{1}$ Department of Biochemistry and Cancer Research Institute, Seoul
National University College of Medicine, Seoul 110-799, Korea
${ }^{2}$ Department of Biochemistry and Molecular Biology, Sungkyunk-
wan University School of Medicine, Suwon 440-746, Korea
${ }^{3}$ Corresponding author: Tel, +82-2-740-8247; Fax, +82-2-744-4534;
E-mail, juhnn@snu.ac.kr
}

Accepted 12 December 2000

Abbreviations: $\mathrm{AC}$, adenylate cyclase; $\mathrm{ACl}, \mathrm{AC}$ isoform I; $\mathrm{CAMP}$, cyclic adenosine monophosphate; GAPDH, glyceraldehyde-3-phosphate dehydrogenase; GPCR, G protein coupled receptor; IBMX, 3isobutyl-1-methylxanthine; $\alpha$-MSH, $\alpha$-melanocyte stimulating hormone; PKA, cAMP dependent protein kinase; RT-PCR, reversetranscription polymerase chain reaction

\begin{abstract}
The terminal differentiation of malignant melanoma cells is known to be induced by activating cAMP signaling pathway with $\alpha$-MSH or cAMP analogues. However, sustained activation of cAMP signaling system that induces the differentiation of melanoma cells, also induces the desensitization of the pathway at the receptor level. Nevertheless, the adaptation of adenylate cyclase (AC) expression by sustained activation of CAMP signaling system has not been clearly understood. This study was performed to examine whether the sustained activation of cAMP system induce changes in the expression AC isoforms as an adaptation mechanism. Treatment of B16/F10 murine melanoma cells with 100 mM forskolin for 6 days resulted in differentiation, melanin accumulation and increased expression of tyrosine hydroxylase mRNA. In the forskolin-treated melanoma cells, change in expression of various $A C$ isoform at the transcription level was detected by reverse-transcription polymerase chain reaction (RT-PCR). Expression of AC isoform mRNA: ACI, III, VI, VII, and IX increased to the level of $196-392 \%$ of the control whereas the level of ACIl was decreased by $30 \%$. The CAMP concentration was increased both in basal and $\alpha-\mathrm{MSH}$ stimulated cells, but the AC activity was decreased in the forskolin treated cells. Thus, these results suggest that sustained activa-
\end{abstract}

tion of cAMP system induces differential expression of $A C$ isoforms, which results in increase of cAMP accumulation.

Keywords: cAMP, adenylate cyclase, cyclic nucleotide phosphodiesterase, cAMP dependent protein kinase, G protein, RT-PCR

\section{Introduction}

Malignant melanoma originates from melanocytes in the basal layer of epidermis, and its incidence is increasing rapidly in the United States and Europe (Herlyn, 1993). Very high fatality could result from this cancer unless it is diagnosed and treated at an early stage. In rare cases, however, malignant melanoma regresses spontaneously by terminal differentiation of the cancer cells. Such spontaneous terminal differentiation can often be induced by activating cAMP signaling pathway with $\alpha$ melanccyte stimulating hormone $(\alpha-\mathrm{MSH})$ (Sukhanov et al., 1993) or with dibutyryl cAMP (Giuffre et al., 1988). Understanding the mechanism of this spontaneous regression of melanoma can contribute to the development of a new therapy not only for melanoma but also for other cancers. Thus, defining the explicit molecular events underlying melanoma development and progression represents areas of intense investigation (Meier et al., 1998).

The differentiation-inducing $\alpha-\mathrm{MSH}$ binds to its specific receptor located at the external surface of melanocytes and melanoma cells, and the resulting activated receptor then activates stimulatory GTP-binding proteins (Gs), which in turn stimulates adenylate cyclase to produce cAMP (Jeong et al., 1998 and Shah, 1999). The cAMP, as a second messenger, activates CAMP-dependent protein kinase (PKA), which in turn phosphorylates serine or threonine residue in many target proteins including those involved in diverse cellular functions such as metabolism, growth, differentiation, melanin synthesis, and cytokine production (Gilchrest et al., 1984; Rees and Healy, 1997). During the cAMP-induced melanoma cell differentiation, diverse signaling pathways are involved including phosphatidylinositol 3kinase/p70(S6)-kinase (Busca et al., 1996), small G protein Rho (Busca et al., 1998), mitogen-activated protein kinase (Englaro et al., 1998), transcription factor microphthalmia (Bertolotto et al., 1998), proto-oncogene cmet (Rusciano et al., 1999), and cell cycle regulators (Haddad et al., 1999). 
Sustained activation of cAMP signaling system that induces the differentiation of melanoma cells, on the other hand, also induces the desensitization of the pathway. Persistent stimulation of the cell surface receptors such as G protein coupled receptors (GPCR) dose not generally bring about a continuous response as the cell adapts to the presence of the stimulus and become desensitized. Receptor desensitization fulfills an important physiological role by acting as the feedback mechanism limiting both acute and chronic over-stimulation of the cascade. Furthermore, GPCR desensitization provides an effective mechanism by which information transduced by multiple GPCR inputs in a single cell can be filtered and integrated into a meaningful biological system (Ferguson and Caron, 1998). GPCR desensitization is known to involve the summation of several distinct events: uncoupling of receptors from their heterotrimeric G proteins, internalization of receptors to endosomes, and down regulation. Sustained activation of cAMP system is achieved by increasing the concentration of cellular cAMP, the key regulator of the CAMP signaling pathway. Its formation from ATP is catalyzed by adenylate cyclase (AC) while its degradation is catalyzed by cyclic nucleotide phosphodiesterase (PDE). Therefore, it is potentially possible that the adaptation of cAMP system to the sustained activation can also take place downstream of the receptor such as AC, PDE, and cAMP dependent protein kinase (PKA) (Houslay, 1998). However, the adaptation of $A C$ and PDE expression to sustained activation of CAMP signaling system has not yet been clearly recognized.

Mammalian AC is encoded by at least nine genes, and each isoform seems to have different kinetic and regulatory properties such as the response to calcium ions, beta gamma subunits of $\mathrm{G}$ proteins and protein kinase C (Sunahara et al., 1996). Such multiplicity of $A C$ isoforms, together with the isoform multiplicity of PDE and PKA, is suggested to play an important role in the regulation of the cAMP signaling system in intracellular targeting, cross-talk between a wide variety of other signaling systems, and flux-controlled sensitivity (Houslay and Milligan, 1997).

This study was performed to examine whether the sustained activation of cAMP system induces changes in the expression of $A C$ isoforms. Thus, using reversetranscription polymerase chain reaction (RT-PCR), the expression of $A C$ isoforms were analyzed in murine melanoma cells differentiated by forskolin treatment.

\section{Materials and Methods}

\section{Materials}

$\alpha-\mathrm{MSH}$, forskolin, bovine serum albumin, EGTA, HEPES, 3-isobutyl-1-methylxanthine (IBMX), and GTP were ob- tained from Sigma; agarose and reverse transcriptase [Superscript II RNase $\mathrm{H}(-)$ Reverse transcriptase] were from GIBCO BRL; phosphocreatine, creatine phosphokinase were from Roche Diagnostics; Taq polymerase was from TaKaRa. All other reagents were of analytical grade.

\section{Cell culture}

B16-F10 mouse melanoma cells were purchased from American Type Culture Collection, and cells were cultured in Dulbecco's modified Eagle's medium with $10 \%$ fetal calf serum, $100 \mathrm{IU} / \mathrm{ml}$ penicillin and $50 \mu \mathrm{g} / \mathrm{ml}$ streptomycin in a humidified atmosphere containing $5 \% \mathrm{CO}_{2}$ in air at $37^{\circ} \mathrm{C}$. The cells were treated with forskolin for 6 days by replacing fresh medium containing $100 \mu \mathrm{M}$ forskolin in DMSO every other day.

\section{Determination of melanin content}

For melanin determination, cells from a confluent $6 \mathrm{~cm}$ diameter dish were harvested and homogenized in a 1.0 $\mathrm{ml}$ homogenization buffer containing $0.05 \mathrm{M} \mathrm{Na}_{2} \mathrm{PO}_{4}$, 200 nM PMSF, and 1X PIC. Part of the homogenate $(800 \mu \mathrm{l})$ was solubilized in $200 \mu \mathrm{l}$ of $1 \mathrm{M} \mathrm{NaOH}$, and the samples were incubated at $60^{\circ} \mathrm{C}$ for $1 \mathrm{~h}$ and vortexed to solubilize the melanin. Absorbance of melanin was measured at $405 \mathrm{~nm}$ with a spectrophotometer, and melanin content was expressed as A405 per mg-protein. The protein content of the homogenate was determined by the Lowry method with bovine serum albumin as the reference standard (Lowry et al., 1951).

\section{Quantification of tyrosine hydroxylase mRNA}

The quantification of tyrosine hydroxylase mRNA was carried out by RT-PCR (Busca et al., 1996). In brief, total cellular RNA was prepared from control and forskolin-treated mouse melanoma B16 cells (Chomczynski and Sacchi, 1987), and the RNA (3 $\mu \mathrm{g})$ was reverse transcribed using the reverse transcriptase. The cDNA obtained was subjected to 26 cycles of PCR $\left(94^{\circ} \mathrm{C}, 1\right.$ $\min ; 55^{\circ} \mathrm{C}, 1 \mathrm{~min} ; 72^{\circ} \mathrm{C}, 2 \mathrm{~min}$ ) using the following specific primers for the mouse tyrosine hydroxylase gene: 5 'CATTTTTGATTTGAGTGTCT and 5'-TGTGGTAGTCGTCTTTGT CC, and an 1191-base pair PCR product was amplified. Specific primers for the glyceraldehyde-3phosphate dehydrogenase (GAPDH) were added as a control for the same reverse transcriptase product. The primers used were 5'-ACCACAGTCCATGCCATCAC-3' and 5'-TCCACCACCCTGTTGCTGTA, and gave rise to an amplified PCR product of 495 base pair. Preliminary trials showed that, after 26 cycles of PCR, the reaction remained exponential. The PCR products were electrophoresed on $1 \%$ agarose gel containing ethidium bromide. The density of DNA band visualized by ultraviolet light was measured using a gel documentation system and the NIH Image $\mathrm{J}$ software. 


\section{RNA isolation and semi-quantitative RT-PCR of AC isoforms}

The total RNA was isolated from cultured cells using the acid guanidinium thiocyanate phenol chloroform extraction method (Chomczynski and Sacchi, 1987). A series of four progressive dilutions was made by mixing varying amount of RNA from the forskolin-treated and the control sample to make a constant amount of total RNA in a constant volume to measure the relative amount of mRNA using the method of Nicoletti and Sassy-Prigent (1996). Three micrograms of the diluted RNA were reverse transcribed by reverse transcriptase and oligo-dT primers. The resulting cDNA was amplified using primers specific for each $A C$ isoform. The primers used were as follows; for ACI 5'-AAG ATT AAG ACC ATT GGG AGC ACT TAC and 5'-CAC ATT GAC TGTGTTTCCCCAGATGTCG, for ACIl (Sohma et al., 1999), for ACIl 5'CGTGTCACT CTCCATATTC and 5'-CCTTGTTCACATCTGACTC, for ACIII 5'-CATCGAGTGTCTACGCTTC and 5'-GGATGACCTGTGTCTCTTCT, for AC IV 5'TTCTTCACACTCCTCGTCC and 5'-CGTCCTGTTGTGTGTCCTG, for AC V 5'-ATCGAGCTCATCTACGTGC and 5'-AGCATGCAGATACAGAGCC, for AC VI 5'-CTGCTTGTGTTCATCTCTG and 5'-GACGCTAAGCAGTAGATCA, for ACVII 5'-CCAGTTATTTAGAGAGAGACCTG and 5'-CTTGCTCATCAGGGCCATGCTAA, for AC VIII 5'-GGACAGCAGCTGGAGTACACAGC and 5'-CCTGATCCTTCAGGATGAGATAG, and for ACIX 5'-AGCTTATCCTCACCTTCTTCTTCCTC and 5'-AGGACACGGTAGCACTCCTTGCC (Emala et al., 1998). For quantification, the optimal amplification conditions such as magnesium concentration, annealing temperature, and amplification cycle number for each isoform in B16-F10 cells were respectively determined by preliminary experiments and the amplified products were confirmed by DNA sequence analysis using the automatic DNA sequencer. The GAPDH gene was amplified using the same samples in order to compare the initial amount of mRNA. The amplified DNA products were separated on an agarose gel containing ethidium bromide, and the DNA band density was measured using a gel documentation system and the NIH Image $\mathrm{J}$ software. The amount of mRNA was calculated from a linear regression curve made of the measured density, and it was expressed as a percentage to the control.

\section{Measurement of cAMP Accumulation}

From the B16-F10 melanoma cells in a 24-well plate, growth medium was removed and then cells were incubated in $500 \mu \mathrm{l}$ serum-free Dulbeccos modified Eagles medium containing $100 \mu \mathrm{M}$ IBMX and in the presence or absence of $10 \mu \mathrm{M} \alpha-\mathrm{MSH}$ for $30 \mathrm{~min}$ at $37^{\circ} \mathrm{C}$. The treatment was terminated by aspiration of medium and addition of $2.5 \mathrm{M}$ perchloric acid. Then, the acid extracts were neutralized with $4.2 \mathrm{M} \mathrm{KOH}$, and the neutralized extract was frozen at $-20^{\circ} \mathrm{C}$ until assay (Brown et al., 1971). The cAMP levels were determined by competitive binding with $\left[{ }^{3} \mathrm{H}\right] \mathrm{cAMP}$ to a cAMP binding proteins, which was prepared by expressing the regulatory subunit Rl $\alpha$ of cAMP dependent protein kinase in $E$. coli. Production of CAMP was normalized to the amount of acid-insoluble protein.

\section{Determination of AC activity}

B16-F10 melanoma cells were harvested and homogenized in ice cold buffer containing $0.25 \mathrm{M}$ sucrose, 10 $\mathrm{mM}$ Tris- $\mathrm{HCl}(\mathrm{pH} 7.5)$, and $10 \mathrm{mM} \mathrm{MgCl}_{2}$. Homogenates were centrifuged at $20,000 \mathrm{~g}$ at $4^{\circ} \mathrm{C}$ for $20 \mathrm{~min}$. Pellets were rehomogenized and washed twice with the above buffers, recentrifuged, and resuspended in $10 \mathrm{mM}$ Tris$\mathrm{HCl}$ and $10 \mathrm{mM} \mathrm{MgCl}_{2}, \mathrm{pH}$ 7.5. Fresh membranes were used in all experiments. The adenylate cyclase assay was carried out as described by Ammer and Schulz (1997) with modification. Adenylate cyclase was determined in a reaction mixture $(100 \mu \mathrm{l})$ containing $40 \mathrm{mM}$ Tris- $\mathrm{HCl}$, pH 7.4, 0.2 mM EGTA, $100 \mathrm{mM} \mathrm{NaCl}, 10 \mathrm{mM}$ $\mathrm{MgCl}_{2}, 0.5 \mathrm{mM}$ ATP, $5 \mu \mathrm{g} / \mathrm{ml}$ phosphocreatine, $5 \mathrm{IU} / \mathrm{ml}$ creatine phosphokinase, $10 \mu \mathrm{M}$ GTP, and $0.5 \mathrm{mM}$ IBMX. Reactions were started by the addition of $5-100$ $\mu \mathrm{g}$ of membrane protein, incubated for $10 \mathrm{~min}$ at $30^{\circ} \mathrm{C}$, and stopped with $2.1 \mathrm{M}$ perchloric acid followed by neutralization with $2.0 \mathrm{M} \mathrm{KOH}$. The amount of cAMP generated was determined by CAMP binding assay (Brown et al., 1971), and adenylate cyclase activity was calculated as $\mathrm{pmol} / \mathrm{mg}$ of protein min.

\section{Statistical analysis}

Results of mRNA expression were analyzed using the two tailed paired t-test, and other results were analyzed using Student t-test. Results were expressed as mean \pm standard deviation (S.D.), and a probability level of 0.05 or smaller was used for statistical significance. All experiments were repeated at least three times in duplicate or triplicate.

\section{Result}

\section{Differentiation of $\mathrm{B} 16 / \mathrm{F} 10$ cells by forskolin treat- ment}

To confirm whether B16/F10 melanoma cells were differentiated by forskolin treatment, cell morphology, melanin production, and expression of tyrosine hydroxylase were analyzed. The dendric morphology of the melanoma cells treated with $100 \mu \mathrm{M}$ forskolin for 6 days became more pronounced as compared with the untreated cells (Figure 1A). The morphology of differentiated melanoma cells reverted to undifferentiated state when forskolin removed from the cultured medium (data not shown). The production of melanin, as one of the dif- 
A

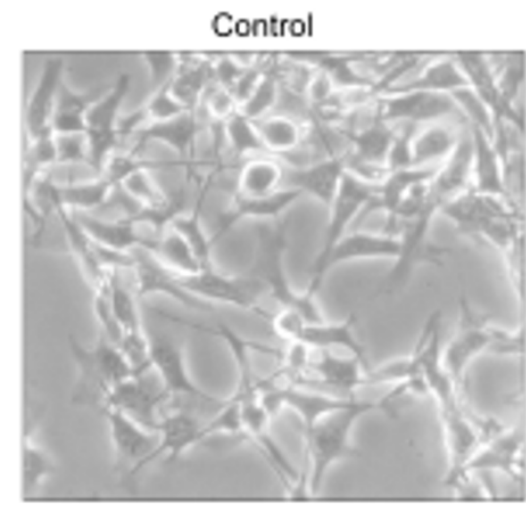

B

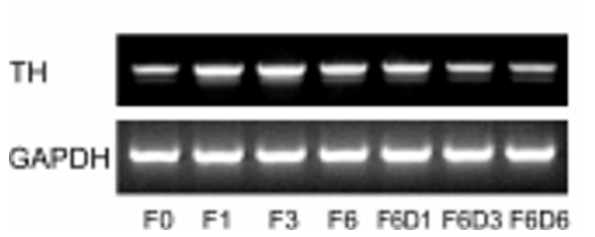

D

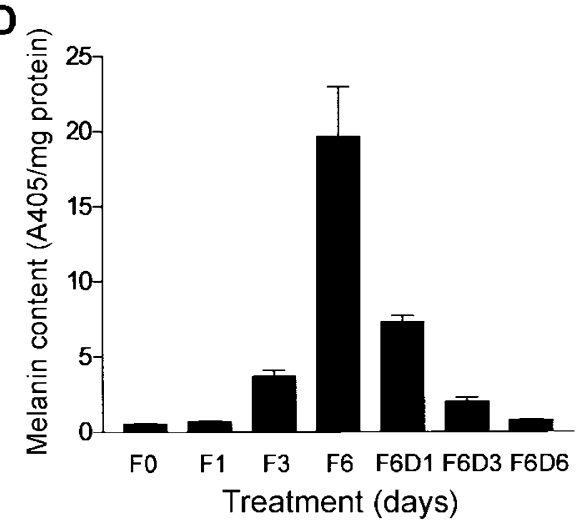

C

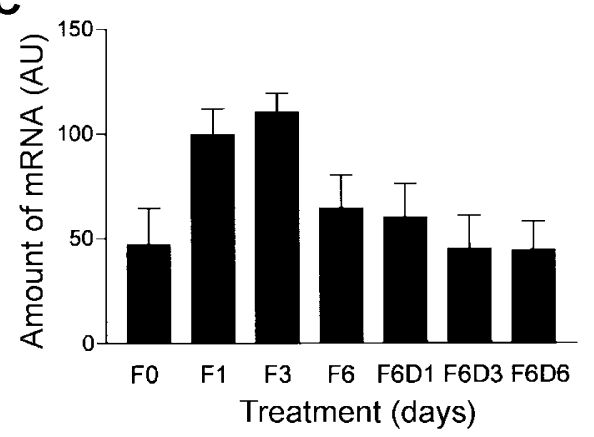

Figure 1. Differentiation of B16-F10 melanoma cells induced by treatment with forskolin. (A) Morphological differentiation (X300), (B) Electropherogram of RTPCR product of tyrosine hydroxylase (TH), (C) Expression of tyrosine hydroxylase analyzed by densitometry of the RT-PCR products, (D) Accumulation of melanin. B16-F10 melanoma cells were treated with $100 \mathrm{mM}$ forskolin in $10 \%$ fetal calf serum-containing medium for indicated duration (F1, F3, F6), and the cells treated with forskolin for 6 days were subsequently grown without forskolin for the indicated duration (F6D1, F6D3, F6D6).

ferentiation marker of melanocytes and melanoma cells, was analyzed in B16-F10 melanoma cells following forskolin treatment. The melanin levels in these cells increased as the duration of the forskolin treatment increased, and reached the peak at day 6 . When forskolin was removed after treatment for 6 days, the production of melanin decreased gradually and reached the basal level by 6 th day (Figure 1D). In the forskolin treated B16-F10 melanoma cells, the expression of tyrosine hydroxylase, a key enzyme in the melanin synthesis pathways, increased sharply on the day 1 and reached peak on day 3. After removal of forskolin, the expression of tyrosine hydroxylase mRAN returned to the basal level on day 3 (Figure 1B and C).

\section{Changes in the expression of $\mathrm{AC}$ isoforms in} forskolin treated cells

The expression of mRNA of AC isoforms were analyzed by semi-quantitative RT-PCR in B16-F10 melanoma cells. The mRNA expression of $\mathrm{ACl}, \mathrm{III}, \mathrm{VI}, \mathrm{VII}$, and IX increased to $222 \%, 271 \%, 201 \%, 196 \%$, and $392 \%$ of the control, respectively, by treatment with $100 \mu \mathrm{M}$ forskolin for 6 days (Figure 2). In contrast, the expression of ACII decreased to $31.3 \%$ of the control. In addition, ACV was not amplified enough for detection, and ACIV and ACVIII were not amplified enough for a quantitative 
A

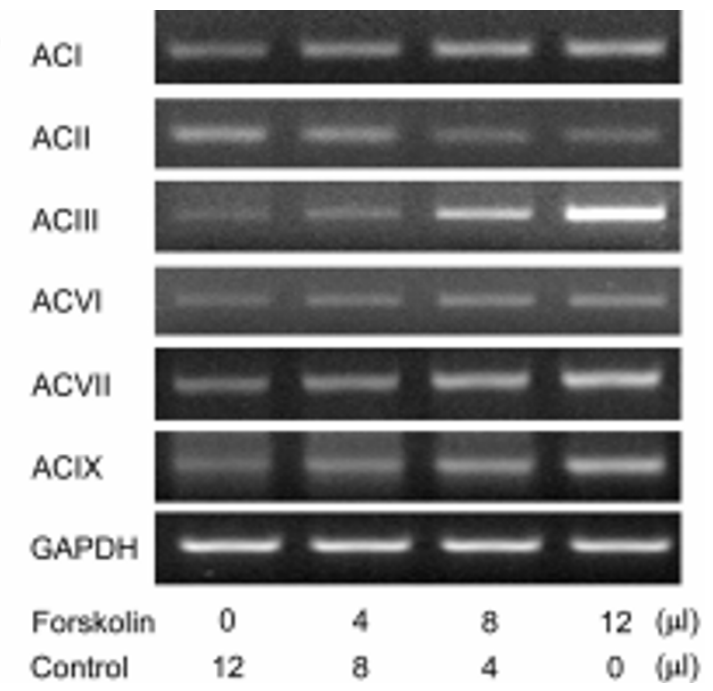

B

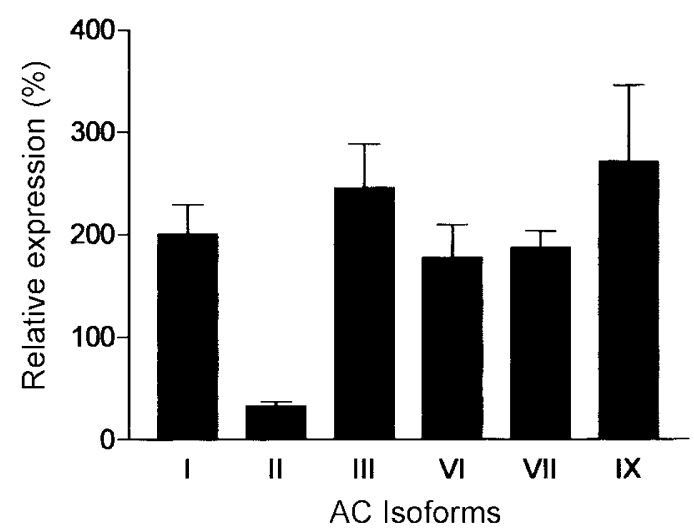

Figure 2. Expression changes in AC isoform mRNA in B16-F10 melanoma cells differentiated by treatment with forskolin. (A) Representative electropherogram of RT-PCR product of AC isoforms, (B) Expression of AC isoforms analyzed by densitometry of the RT-PCR products. After B16/F10 melanoma cells were treated with $100 \mu \mathrm{M}$ forskolin for 6 days, total RNA was prepared and the expression of each $\mathrm{AC}$ isoform was analyzed by semi-quantitative RT-PCR using isoform-specific primers. The amount of mRNA was expressed as percentage of the untreated control, and is mean \pm standard deviation of at least 3 independent experiments. All the data presented displayed statistically significant difference from the control group ( $<<0.05$, paired t-test, two-tailed).

analysis by the RT-PCR method.

\section{Changes in the AC activity in the forskolin-treated B16/F10 melanoma cells}

AC activity was assayed to see the increment of mRNA expression of $A C$ isoforms could result in an decrease of AC activity. Basal and forskolin stimulated AC activity were significantly decreased in the forskolin treated melanoma cells (Table 1).

\section{cAMP response in the forskolin-treated B16/F10 melanoma cells}

Table 1. Changes in AC activity in B16-F10 melanoma cells treated with forskolin. The AC activity was determined, in the presence or absence of $100 \mu \mathrm{M}$ forskolin, in the fresh membranes prepared from the forskolintreated and control cells. The formed cAMP was quantified by competitive binding with $\left.{ }^{3} \mathrm{H}\right] \mathrm{CAMP}$ to a CAMP binding proteins after stimulation with buffer only (basal) or buffer containing $100 \mu \mathrm{M}$ forskolin for $10 \mathrm{~min}$.

\begin{tabular}{lc}
\hline & $\begin{array}{c}\text { AC activity } \\
(\mathrm{pmol} / \mathrm{mg} \text { protein } \mathrm{min})\end{array}$ \\
\hline Control & \\
$\quad$ Unstimulated & $87.7 \pm 13.1$ \\
$\quad$ Forskolin stimulated & $478 \pm 105$ \\
Forskolin treated & \\
$\quad$ Unstimulated & $10.9 \pm 2.4$ \\
Forskolin stimulated & $345 \pm 29$ \\
\hline
\end{tabular}

Table 2. Changes in accumulation of cAMP in B16-F10 melanoma cells treated with forskolin. After B16/F10 melanoma cells were treated with 100 $\mu \mathrm{M}$ forskolin for 6 days, cAMP levels were analyzed by competitive binding with $\left.{ }^{3} \mathrm{H}\right] \mathrm{CAMP}$ to a cAMP binding proteins after stimulation with buffer only (basal) or buffer containing $10 \mu \mathrm{M} \alpha-\mathrm{MSH}$ for $30 \mathrm{~min}$

\begin{tabular}{lc}
\hline & cAMP $(\mathrm{pmol} / \mathrm{mg}$ protein $)$ \\
\hline Control & $5.3 \pm 3.2$ \\
Basal & $2266 \pm 489$ \\
$\alpha-\mathrm{MSH}$-stimulated & $1109 \pm 736$ \\
Forskolin treated & $5083 \pm 1102$ \\
$\quad$ Basal & \\
$\alpha-\mathrm{MSH}$-stimulated & \\
\hline
\end{tabular}

Analysis of the cAMP levels in B16/F10 melanoma cells following forskolin treatment showed, the basal level of CAMP was $1109 \mathrm{pmol} / \mathrm{mg}$ protein and about 4.1 -fold higher than the control (5.3 pmol/mg protein). Stimulation with $\alpha-\mathrm{MSH}$ increased cAMP level sharply to 2266 $\mathrm{pmol} / \mathrm{mg}$ protein in the control, and $5083 \mathrm{pmol} / \mathrm{mg}$ protein in the forskolin-treated B16/F10 melanoma cells. Thus 2.2-fold more cAMP was accumulated in the forskolin-treated cells when they were stimulated by $\alpha$ MSH (Table 2).

\section{Discussion}

The present study was carried out to examine whether the sustained activation of CAMP system induces changes in the expression $A C$ isoforms. We found that sustained activation of adenylate cyclase with forskolin induces differential expression of AC isoforms at the mRNA level, which results in accumulation of CAMP and decrease of AC activity in the B16-F10 melanoma cells. Such result demonstrates that the AC activity can be modulated depending the activation of cAMP system, therefore, the change in the $\mathrm{AC}$ expression may be considered as an adaptive response of the system. It may be an example of post-receptor adaptation of CAMP signaling system.

The up regulation of all the $A C$ isoforms except $A C l$ I indicates that there is some positive feedback mechani- 
sms. Such positive feedback loop of AC expression might play an important role in forskolin-induced differentiation of B16-F10 melanoma cells. However, it is not clear whether such positive feedback loops could apply to other mechanisms that activate cAMP systems, induced by $\beta$-adrenergic agonists or cAMP analogues, and expression of a constitutively activated mutant of stimulatory $G$ protein. It should make it clear whether there exists any cell type specificity in the positive feed back loop of $A C$ expression induced by forskolin treatment, with regard to the specific role of activated cAMP system in the cellular proliferation, differentiation, and apoptosis.

The extent of increase in AC isoform mRNAs in this study was significantly different among each $A C$ isoforms; some increased markably and the others slightly. Such differential expression imply that the same stimuli, the forskolin treatment, resulted in different effects on the expression of each $A C$ isoform, reflecting the fact that mammalian AC's are encoded by at least 9 separate genes which are not clustered, and localized on different chromosomes in the human genomes (Hanoune et al., 1997). The promoter regions of all the AC genes are not known, but the expression of individual $A C$ isoform, based our results, would likely be regulated by different mechanisms. The expression of $A C$ isoforms changed in a similar pattern to that of tyrosine hydroxylase as the duration of forskolin treatment increased. The mRNA expression reached the peak on the day of 3 , and then decreased sharply or maintained higher level depending on the isoforms. The expression of ACII mRNA reached the peak on day 3 but decreased sharply after the peak so that it reached a decreased level compared to the control on the day 6 (data not shown). In addition, the expression of ACll is suggested to be regulated under different mechanisms from other isoforms.

$\mathrm{AC}$ isoforms have different kinetic and regulatory properties, such as regulation by inhibitory $\mathrm{G}$ proteins, betagamma subunits of $\mathrm{G}$ proteins, calcium, calmodulin, and protein kinases (Hanoune et al., 1997). Thus the observed differential increase in the expression of $A C$ isoforms may result in both the increase of the enzyme activity and the changes in the regulatory properties in the melanoma cells. The changes in the regulatory properties of cAMP system can change the cellular response of signaling systems coupled to the cAMP system including hormones and neurotransmitters. Such changes might contribute to the differentiation process of B16-F10 melanoma cells by changing the expression patterns of many target genes of CAMP dependent protein kinase.

Though treatment with forskolin increased the expression of $A C$ isoform mRNA, AC activity decreased significantly in this study. Such decrease can be resulted from decrease in protein concentration by either enhanced degradation or reduced synthesis. Thus, the analysis of protein expression of each isoform is needed to prove this possibility. The observed decrease in AC activity could result from the inhibition by protein kinases. This mechanism is supported by the reports that AC activity is reduced by cAMP dependent phosphorylation (Premont et al., 1992) and that the underlying mechanism may be the inhibitory phosphorylation of ACVI by PKA on Ser 674 (Chen et al., 1997). Protein kinase $C$ also inhibits ACVI activity during desensitization of the A2a-adenosine receptormediated cAMP response (Lai et al., 1997). The observed decrease in the AC activity is suggested as a feedback inhibition of sustained activation of cAMP system to prevent excessive stimulation of the system.

The level of cAMP was significantly increased in the basal and the $\alpha-\mathrm{MSH}$ stimulated B16/F10 melanoma cells treated with $100 \mu \mathrm{M}$ forskolin for 6 days. The increase in cAMP levels can result from increased synthesis, decreased degradation, or both. Because both the basal and the forskolin-stimulated AC activity were decreased in forskolin treated cells, the increase in cAMP accumulation is more likely from reduced degradation of cAMP. Thus the analysis of the activity change of the cAMP-degrading enzyme, cyclic nucleotide phosphodiesterase, would be helpful for explaining the mechanism of increased cAMP response in the forskolin-treated SH-SY5Y neuroblastoma cells (Cho et al., 2000). Another possibility is the activation of $\mathrm{AC}$ by $\alpha-\mathrm{MSH}$ is not inhibited in contrast to the activation by forskolin, which must be analyzed to understand the mechanism of the increased cAMP accumulation. The resulting increase in cellular cAMP level increases the activity of PKA, which regulates cellular metabolism and gene expression by phosphorylating various target genes including those involved in the differentiation of B16-F10 melanoma cells (Daniel et al., 1998).

Treatment with forskolin induces differentiation of B16/ F10 melanoma cells as recognized by the morphological changes, increase in melanin synthesis, and increased expression of tyrosine hydroxylase in this study. Sustained activation of the CAMP pathway is known to result in accumulation of large quantities of melanin and terminal differentiation of melanocytes (Medrano et al., 1994). However, the changes in the melanin synthesis and tyrosine hydroxylase expression were reverted to its basal level when forskolin was removed from the medium after 6-days of treatment, suggesting that the observed changes are reversible in nature. It seems to be important to find what makes differentiation of melanoma cells irreversible, and studies like differentiation induction subtraction hybridization (DISH) may be useful for this purpose (Huang et al., 1999).

Because numerous genes and signaling systems are involved, including the small GTP-binding protein Rho, phosphatidylinositol 3-kinase/p70(S6)-kinase, extracellular signal-regulated kinase (ERK), NF- $\mathrm{KB}$ (Englaro et al., 
1999), microphthalmia-associated transcription factor (Aberdam et al., 1998), in the differentiation of B16-F10 melanoma cells, the contribution of differential expression of AC isoforms observed in this study to the differentiation of the forskolin-treated melanoma cells is not clear at present. Thus it is not certain whether such change in the $\mathrm{AC}$ isoform expression is a simple adaptation mechanism for sustained activation of cAMP system, or it is involved directly in the differentiation procedures. However, the differential expression of AC in concert with multi-potent AC signaling system play an important role in the differentiation process of the melanoma cells. Such implication is supported by some studies to show that cyclic AMP is a key messenger in the regulation of skin pigmentation (Busca and Ballotti, 2000), and that there exists a melanocyte-specific Ras exchange factor directly regulated by CAMP (Busca et al., 2000).

This study suggests that sustained activation of CAMP signaling system induces differential expression of $A C$ isoforms, resulting in increase cAMP accumulation. This differential expression of $A C$ isoforms may further indicate that there is a positive feedback loop in AC expression in B16 melanoma cells, and that it may be involved in the process of differentiation of B16-F10 melanoma cells by changing phosphorylation patterns of target genes.

\section{Acknowledgement}

This study was supported by the grant from Seoul National University College of Medicine Fund (1996) and S.N.U. POSCO Research Fund (96-08-2095).

\section{References}

Aberdam, E., Bertolotto, C., Sviderskaya, E. V., de Thillot, V., Hemesath, T. J., Fisher, D. E., Bennett, D. C., Ortonne, J. P. and Ballotti, R. (1998) Involvement of microphthalmia in the inhibition of melanocyte lineage differentiation and of melanogenesis by agouti signal protein. J. Biol. Chem. 273: 1956019565

Ammer, H. and Schulz, R. (1997) Enhanced stimulatory adenylyl cyclase signaling during opioid dependence is associated with a reduction in palmitoylated Gs alpha. Mol. Pharmacol. 52: 993-999

Bertolotto, C., Abbe, P., Hemesath, T. J., Bille, K., Fisher, D. E., Ortonne, J. P. and Ballotti, R. (1998) Microphthalmia gene product as a signal transducer in CAMP-induced differentiation of melanocytes. J. Cell Biol. 142: 827-835

Brown, B. L., Albano, J. D., Ekins, R. P. and Sgherzi, A. M. (1971) A simple and sensitive saturation assay method for the measurement of adenosine 3':5'-cyclic monophosphate. Biochem. J. 121: 561-562
Busca, R., Abbe, P., Mantoux, F., Aberdam, E., Peyssonnaux, C., Eychene, A., Ortonne, J. P. and Ballotti, R. (2000) Ras mediates the cAMP-dependent activation of extracellular signal-regulated kinases (ERKs) in melanocytes. EMBO J. 19: 2900-2910

Busca, R. and Ballotti, R. (2000) Cyclic AMP a key messenger in the regulation of skin pigmentation. Pigment. Cell Res. 13: 60-69

Busca, R., Bertolotto, C., Abbe, P., Englaro, W., Ishizaki, T., Narumiya, S., Boquet, P., Ortonne, J. P. and Ballotti, R. (1998) Inhibition of Rho is required for CAMP-induced melanoma cell differentiation. Mol. Biol. Cell 9: 1367-1378

Busca, R., Bertolotto, C., Ortonne, J. P. and Ballotti, R. (1996) Inhibition of the phosphatidylinositol 3-kinase/p70(S6)-kinase pathway induces B16 melanoma cell differentiation. J. Biol. Chem. 271: 31824-31830

Chen, Y., Harry, A., Li, J., Smit, M. J., Bai, X., Magnusson, R., Pieroni, J. P., Weng, G. and lyengar, R. (1997) Adenylyl cyclase 6 is selectively regulated by protein kinase $A$ phosphorylation in a region involved in Galphas stimulation. Proc. Natl. Acad. Sci. USA 94: 14100-14104

Cho, C. H., Cho, D. H., Seo, M. R. and Juhnn, Y. S. (2000) Differential changes in the expression of cyclic nucleotide phosphodiesterase isoforms in rat brains by chronic treatment with electroconvulsive shock. Exp. Mol. Med. 32: 110-114

Chomczynski, P. and Sacchi, N. (1987) Single-step method of RNA isolation by acid guanidinium thiocyanate-phenol-chloroform extraction. Anal. Biochem. 162: 156-159

Daniel, P. B., Walker, W. H. and Habener, J. F. (1998) Cyclic AMP signaling and gene regulation. Annu. Rev. Nutr. 18: 353383

Emala, C. W., Kumasaka, D., Hirshman, C. A. and Lindeman, K. S. (1998) Adenylyl cyclase messenger ribonucleic acid in myometrium: splice variant of type IV. Biol. Reprod. 59: 169175

Englaro, W., Bahadoran, P., Bertolotto, C., Busca, R., Derijard, B., Livolsi, A., Peyron, J. F., Ortonne, J. P. and Ballotti, R. (1999) Tumor necrosis factor alpha-mediated inhibition of melanogenesis is dependent on nuclear factor kappa B activation. Oncogene 18: 1553-1559

Englaro, W., Bertolotto, C., Busca, R., Brunet, A., Pages, G., Ortonne, J. P. and Ballotti, R. (1998) Inhibition of the mitogenactivated protein kinase pathway triggers B16 melanoma cell differentiation. J. Biol. Chem. 273: 9966-9970

Ferguson, S. S. and Caron, M. G. (1998) G protein-coupled receptor adaptation mechanisms. Semin. Cell Dev. Biol. 9: 119-127

Gilchrest, B. A., Vrabel, M. A., Flynn, E. and Szabo, G. (1984) Selective cultivation of human melanocytes from newborn and adult epidermis. J. Invest. Dermatol. 83: 370-376

Giuffre, L., Schreyer, M., Mach, J. P. and Carrel, S. (1988) Cyclic AMP induces differentiation in vitro of human melanoma cells. Cancer 61: 1132-1141

Haddad, M. M., Xu, W., Schwahn, D. J., Liao, F. and Medrano, 
E. E. (1999) Activation of a cAMP pathway and induction of melanogenesis correlate with association of p16(INK4) and p27(KIP1) to CDKs, loss of E2F-binding activity, and premature senescence of human melanocytes. Exp. Cell Res. 253: 561-572

Hanoune, J., Pouille, Y., Tzavara, E., Shen, T., Lipskaya, L., Miyamoto, N., Suzuki, Y. and Defer, N. (1997) Adenylyl cyclases: structure, regulation and function in an enzyme superfamily. Mol. Cell Endocrinol. 128: 179-194

Herlyn, M. (1993) Incidence of melanoma. In Molecular and Celluar Biology of Melanoma, pp 3-4, R. G. Randes Company, Austin.

Houslay, M. D. (1998) Adaptation in cyclic AMP signalling processes: a central role for cyclic AMP phosphodiesterases. Semin. Cell Dev. Biol. 9: 161-167

Houslay, M. D. and Milligan, G. (1997) Tailoring cAMP-signalling responses through isoform multiplicity. Trends Biochem. Sci. 22: 217-224

Houslay, M. D. (1998) Adaptation in cyclic AMP signalling processes: a central role for cyclic AMP phosphodiesterases. Semin. Cell Dev. Biol. 9: 161-167

Huang, F., Adelman, J., Jiang, H., Goldstein, N. I. and Fisher, P. B. (1999) Differentiation induction subtraction hybridization (DISH): a strategy for cloning genes displaying differential expression during growth arrest and terminal differentiation. Gene 236: 125-131

Jeong J. S., Kim I. H., Lee H. J. and Choi Y. C. (1998) Nucleolus contains signal molecules that constitute membranenucleolus linked pathway. Exp. Mol. Med. 30: 205-213

Lowry, O., Rosebrough, N., Fair, A. and Randall, R. (1951) Protein measurement with the Folin phenol reagent. J. Biol. Chem. 193: 265-275

Medrano, E. E., Yang, F., Boissy, R., Farooqui, J., Shah, V., Matsumoto, K., Nordlund, J. J. and Park, H. Y. (1994) Terminal differentiation and senescence in the human melanocyte: repression of tyrosine-phosphorylation of the extracellular signal-regulated kinase 2 selectively defines the two phenotypes. Mol. Biol. Cell 5: 497-509
Meier, F., Satyamoorthy, K., Nesbit, M., Hsu, M. Y., Schittek, B., Garbe, C. and Herlyn, M. (1998) Molecular events in melanoma development and progression. Front. Biosci. 3: D1005-1010

Nicoletti, A. and Sassy-Prigent, C. (1996) An alternative quantitative polymerase chain reaction method [published erratum appears in Anal Biochem 1996 Nov 1; 242(1): 164]. Anal. Biochem. 236: 229-241

Ostrom, R. S., Post, S. R. and Insel, P. A. (2000) Stoichiometry and compartmentation in $\mathrm{G}$ protein-coupled receptor signaling: implications for therapeutic interventions involving G(s). J. Pharmacol. Exp. Ther. 294: 407-412

Premont, R. T., Jacobowitz, O. and lyengar, R. (1992) Lowered responsiveness of the catalyst of adenylyl cyclase to stimulation by GS in heterologous desensitization: a role for adenosine 3',5'-monophosphate-dependent phosphorylation. Endocrinology 131: 2774-2784

Rees, J. L. and Healy, E. (1997) Melanocortin receptors, red hair, and skin cancer. J. Investig. Dermatol. Symp. Proc. 2: 9498

Rusciano, D., Lorenzoni, P. and Burger, M. M. (1999) Regulation of c-met expression in B16 murine melanoma cells by melanocyte stimulating hormone. J. Cell Sci. 112: 623-630

Shah, B. H. (1999) Cholera toxin mediated regulation of the expression of $\mathrm{Gq}$ and G11 GTP binding proteins. Exp. Mol. Med. 31: 89-94

Sohma, H., Hashimoto, E., Shirasaka, T., Tsunematsu, R., Ozawa, H., Boissl, K. W., Boning, J., Riederer, P. and Saito, T. (1999) Quantitative reduction of type I adenylyl cyclase in human alcoholics. Biochim. Biophys. Acta. 1454: 11-18

Sukhanov, V. A., Voronkova, I. M., Shvets, S. V. and Morozova, L. F. (1993) Melanocyte stimulating hormone inhibits growth of amelanotic cells of human malignant melanoma with concomitant changes in concentration of CAMP, phosphtidylinositols, and inositol phosphates. Biokhimiya 58: 221-223

Sunahara, R. K., Dessauer, C. W. and Gilman, A. G. (1996) Complexity and diversity of mammalian adenylyl cyclases. Annu. Rev. Pharmacol. Toxicol. 36: 461-480 